https://www.journal-imab-bg.org

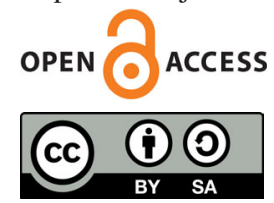

Original article

\title{
ANALYSIS OF THE OPINIONS EXPRESSED BY THE DENTAL AID CONSUMERS IN THE REPUBLIC OF BULGARIA
}

\author{
Evelina Perchinska-Poptodorova ${ }^{1}$, Stayko Spiridonov ${ }^{2}$, Kalina Stefanova ${ }^{3}$ \\ 1) Department of Health Economy, Faculty of Public Health, Medical University \\ - Sofia, Bulgaria \\ 2) Department of Health Policy and Management, Faculty of Public Health, \\ Medical University - Sofia, Bulgaria \\ 3) Subsidiary 'Prof. Ivan Mitev' - Vratsa, Medical University - Sofia, Bulgaria
}

\section{SUMMARY}

Purpose: In the Republic of Bulgaria dental disorders concern the prevailing population. They are cumulative, progressive and are not self-healing. The present paper examines the patient's opinions about the dental care.

Materials and Methods: The paper is based on a research realized in June-December 2016. The research was conducted among patients with dental care using dental services in the capital. The authors investigate their knowledge of the dental package by NHIF, how often they use it, whether their needs have been satisfied, how many of them have additional voluntary health insurance package for dental services and is there any financial benefit.

Results and conclusions: The study shows that the dental healthcare system doesn't meet the needs of the patients.

Keywords: dental care, health insurance, voluntary health insurance, National health insurance fund (NHIF)

\section{INTRODUCTION}

In the Republic of Bulgaria, dental disorders concern the prevailing population. They are cumulative, progressive and are not self-healing. Each and every untreated disorder results in complications that additionally hinder the treatment process. It is hard for patients to learn how to take care of their health by themselves. An additional factor that contributes to them refraining from visiting the dental medicine offices is the so-called additional payment (co-payment) for each activity [1]. The insufficient amount of funds for dental aid deteriorates the negative trends in the dental health of all age groups of the population, an objective impossibility to invest high-quality dental materials and cutting edge methodologies in dental treatment and total refusal of dental service by the population with toothless jaws [2, 3].

The objective of the present article is to analyse the attitudes of patients towards the need of more effective management of the resources necessary for dental aid.
In order to achieve that objective we outlined the following tasks:

1. Analysis of awareness of the inquired persons on the health package of dental services provided by the National Health Insurance Fund.

2. How often do they use the package of dental services paid by the National Health Insurance Fund and is it adequate in terms of their needs?

3. Analysis of the opinion expressed by the inquired persons on the benefits of the additional health-insurance package for dental services and how many of them have such insurance.

\section{MATERIAL AND METHODS}

A questionnaire method is used. In the period of June - December 2016 we ran inquiry survey of 291 actual consumers of dental aid that have used dental services in the city of Sofia.

\section{RESULTS AND DISCUSSION}

The group of persons covered by the inquiry survey are almost evenly distributed by genders. When it comes to the gender distribution - women $(51,2 \%)$ have minimum prevalence over men $(48,8 \%)$. Age distribution of inquired persons is characterized by almost even distribution whereas most persons are aged below $40-23,6 \%$ and the least $16,2 \%$ are in the group aged 51 to 60 , followed by the age group above $60-17,3 \%$. This is logical since with age we observe edentulation of the population and oftentimes the persons of that age group have lower income $[4,5]$. The majority of the inquired persons are inhabitants of the capital city $-69,4 \%$, which is quite à logical bearing in mind the fact that survey was held in the city of Sofia. The next group is one of other towns that have chosen to use dental aid in the capital city $-19,6 \%$ and the last are the persons who inhabit the villages $-11,0 \%$. In that case, the leading reason is the search for highly qualified specialists and offices equipped with cutting edge facilities. 
Fig. 1. Patients' awareness of the health package of dental services in the line of the National Health Insurance Fund.

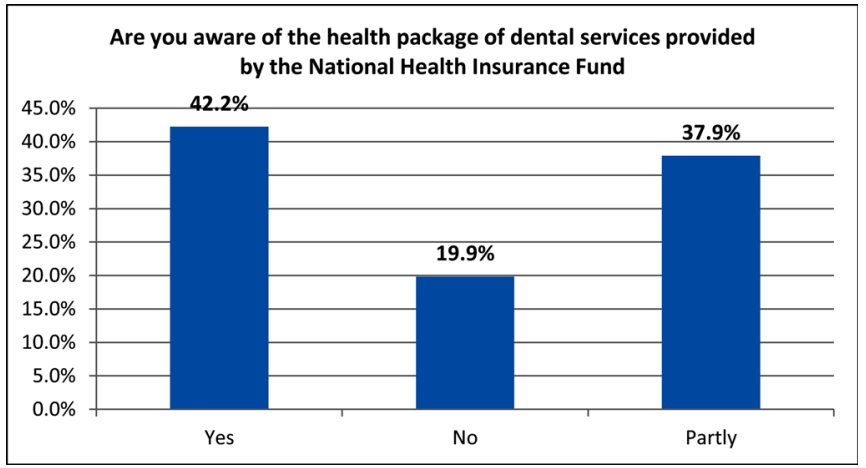

It is worth mentioning that the majority of dental services consumers are not aware of their rights for using services in the line of the mandatory health insurance. Almost one fifth answered that they are not aware of the health package of dental services provided by the National Health Insurance Fund, and 37,9 \% are partially aware. Society is not quite aware of the package provided by the National Health Insurance Fund. It is up to the doctors of dental medicine (if willing) to provide the patients with information about that package of services. Only $42 \%$ of the inquired persons stated that they know what they could use and subsequently it would be paid by the National Health Insurance Fund (figure 1).

Fig. 2. How often do the inquired persons use services in line with the National Health Insurance Fund?

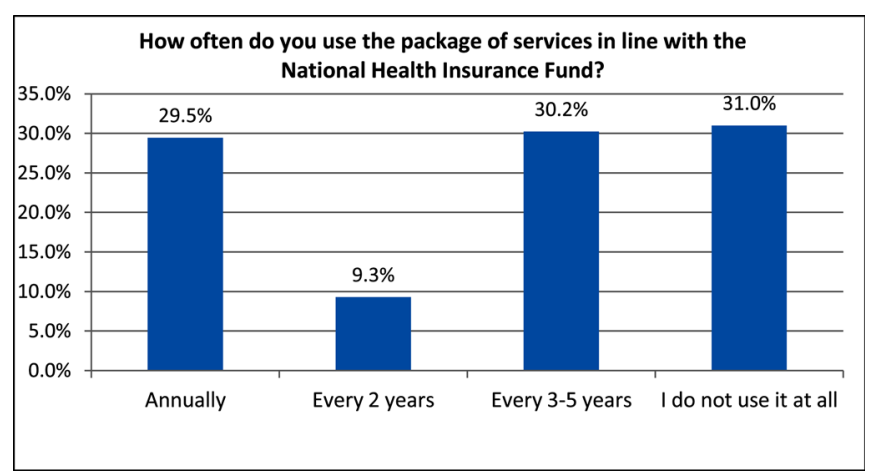

According to the information provided by figure 2only $29,5 \%$ of the inquired persons use annually services in line with the mandatory health insurance. The persons that take advantage of these services every two years is $9,3 \%$ and $30,2 \%$ every 3 to 5 years take that opportunity. It is worth mentioning the exceptionally high share of persons that have never used dental services paid by the National Health Insurance Fund $-31,0 \%$. This is hardly due only to ignorance, but rather some respondents believe that the services covered by the National Health Insurance Fund are negligibly small, while in the case of other persons looking for dentist the only problem that matters is the timeliness of rendering the service, as well as the absence of health-insurance books at the time.
Fig. 3. Adequacy of healthcare package in the line of the National Health Insurance Fund in view of respondents' needs.

\section{Do you believe that package is adequate to your dental aid needs?}

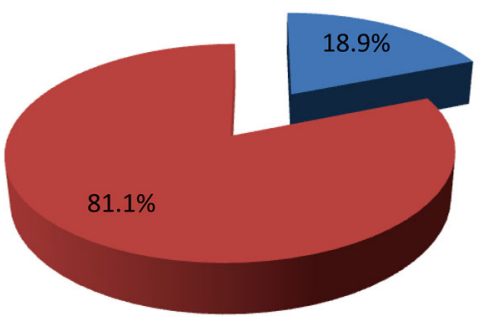

Yes

No

The modern dental aid is procured with cutting-edge equipment, high-tech apparatuses - Xray scanners, lasers, dental 3D scanners, the new technologies in the area of implantology, in orthodontics, oral and maxillofacial surgery, novelties in prosthetic dental medicine turn it into expensive and not easily accessible. Quite logically 81,1 $\%$ of the inquired persons believe the package provided by the National Health Insurance Fund does not adequately satisfy their needs. It is worth mentioning that only 18,9 $\%$ perceive it as a package that covers their needs and expectations (figure 3 ).

Fig. 4. Do you use additional health-insurance package?

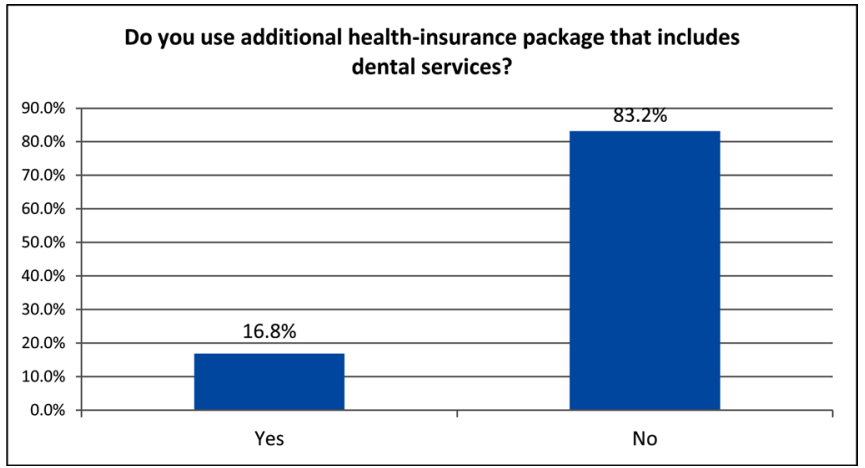

The insurance joint-stock companies that have a general insurance license issued and insurance being their business (voluntary health insurance) offer the insurance product "Dental aid". If insurance was purchased and it includes the package "Dental aid" they reimburse costs incurred for dental services and commodities according to the contractual terms and conditions (the policy). Figure4 shows that only $16,8 \%$ of the inquired persons have such insurance. Unfortunately many respondents $83,2 \%$ do not use such product that provides them with better security if having dental problems, oftentimes gives them discounts in certain dental offices and centres that operate under a contract entered with the insurer. 
Fig. 5. Opinion on additional dental health insurance and its financial effect.

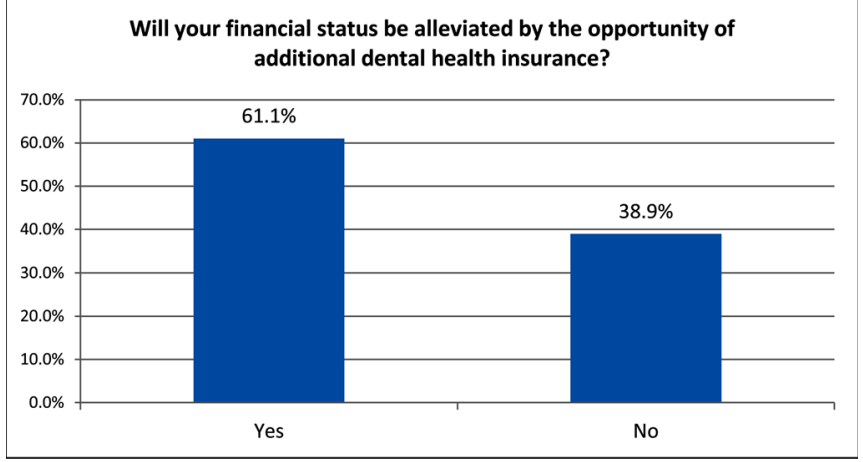

Bulgaria lacks the traditions in insurance and voluntary health insurance. The prevailing part of society cannot assess in an objective manner the benefits of health insurance and its financial effect [6]. Secondly, we should bear in mind the low incomes and the attitude that one may not need it at the moment. Oftentimes dental aid should be provided surprisingly and quite urgently (and this is accompanied by pain on many occasions). In these cases, the health insurance ensures peace of mind and security for the insureds. They would get the treatment they need without bearing financial burden in the shortest term. Hence the great variety of opinions $-61,1 \%$ of the inquired accept that the additional dental health insurance would be economically reasonable, while $38,9 \%$ are not of the same opinion (figure 5).

\section{CONCLUSIONS}

It is well-known that dental medicine is fully operating at the free market. This creates non-equivalence in health care hence the people of lower social-economic positions spend more years of their lives in poor health condition.

Dental aid is being used mainly by working people who have the financial capacity to spend money on their dental health. The prevailing part of the consumers pay directly for these services and over $61 \%$ quite seldom or do not use dental aid in the line of the mandatory health insurance. A very small part of the inquired (below 17\%) have supplementary health insurance that covers dental services.

All this deteriorates the negative trends in the dental health of all age groups of the population. And it is a prerequisite for an objective impossibility to invest highquality dental materials and cutting edge methodologies in dental treatment and total refusal of dental service by the population with toothless jaws. Quite logically all inquired persons stand by the thesis that the state should provide certain social groups with dental aid.

\section{Abbreviation: \\ NHIF - National Health Insurance Fund}

\section{REFERENCES:}

1. Cherkezov T. Key mechanisms for healthcare quality improvement. Medical management and health policy. 2013; 44(2):48-60. [in Bulgarian]

2. Gonchev V. Inequalities in health care - issues in the European Union and Bulgaria. Scientific works of the Rouse University. 2013; 52(8.3):3741. [in Bulgarian]

3. Popov N, Zlatanova T, Mihaylov
R. Prevention realized by voluntary health insurance in Bulgaria 2003 2012. Preventive medicine. VI, 2017; 1(11):20-23. [in Bulgarian] [Internet]

4. Shtereva-Nikolova N, Popov N. Provision of dental aid for elderly people in the Republic of Bulgaria. Jubilee Scientific Session - 60 years of Department "Social medicine" Medical University - Plovdiv. Collection of Reports. Pub. Medical University -
Plovdiv, 2011, p.16-24. [in Bulgarian] 5. Shtereva N, Popov N. Dental aid for elderly people, Chapter V. In: Current problems of aging and old age. Editor Vodenicharov Ts. Simel. 2009. p.166-181 [in Bulgarian]

6. Andreeva-Raynova T, Vodenicharov Ts, Popov N. Challenges faced by health insurance in Bulgaria. Health and science. $2016 \mathrm{Dec} ; 6(4$ (024)):16-19. [in Bulgarian]

Please cite this article as: Perchinska-Poptodorova E, Spiridonov S, Stefanova K. Analysis of the opinions expressed by the dental aid consumers in the Republic of Bulgaria. J of IMAB. 2017 Jul-Sep;23(3):1681-1683.

DOI: https://doi.org/10.5272/jimab.2017233.1681

Received: 07/06/2017; Published online: 21/09/2017

Address for correspondence:

Assoc. Prof. Stayko Ivanov Spiridonov, MD, Department of Health Policy and Management, Faculty of Public Health, Medical University - Sofia.

8, Bialo more str., fl. 5; 1527 Sofia, Bulgaria. Tel.: +359898 642646

E-mail: sspiridonov@abv.bg,

https://www.journal-imab-bg.org 